\title{
DIE ONTWIKKELING VAN 'N REKENAARONDERSTEUNDE TAALONDERRIGPROGRAM OP GROND VAN AFRIKAANSE FOLKLORE
}

\author{
Estelle Kruger \\ Universiteit van Stellenbosch
}

Hierdie artikel doen verslag oor die ontwikkeling en gebruik van 'n rekenaarondersteunde taalonderrigprogram vir addisioneletaalonderrig. In navolging van verskeie teoretici voer die navorser aan dat die pikturale humor soos vervat in T.O. Honiball se strokiesprente as toegepaste Afrikaanse folklore beskou kan word - 'n soort kernliteratuur wat op mondelinge volksverhale berus. Die artikel bespreek die fases en faktore wat die ontwikkeling van die program vir gebruik in 'n virtuele taalklaskamer beïnvloed het, asook die uitkomste en inhoud daarvan. Uiteindelik is die program in 'n kwalitatiewe navorsingsprogram gebruik waar onderwysstudente dit aan die hand van addisioneletaalonderrigbeginsels moes beoordeel.

This article reports on the development and use of a computer assisted language teaching programme for additional language teaching. With the necessary theoretical support, the researcher argues that the pictorial humour contained in the comic strips of T.O. Honiball could be considered as applied Afrikaans folklore based on this language's oral story tradition. The article discusses the phases and factors influencing the development of the programme for use in a virtual language classroom, as well as its outcomes and content. Eventually the programme was used in a qualitative research programme where teaching students evaluated it on the basis of principles for additional language teaching.

\section{Kernbegrippe}

addisioneletaalonderrig, folklore, pikturale humor, rekenaarondersteunde taalonderrig (ROTO), T.O. Honiball, virtuele klaskamer

\section{Key concepts}

additional language teaching, computer assisted language learning (CALL), folklore, pictorial humour, T.O. Honiball, virtual classroom

\section{AGTERGROND EN MOTIVERING}

Opvoeders wat in 'n multikulturele Suid-Afrika letterkunde onderrig, moet kennis dra van die konteks waarbinne leerders hulle individuele verskille en kultuurmanifestasies beleef. As gevolg van persoonlike, maatskaplike en kulturele verskille bestaan die moontlikheid van interkulturele konflik in multikulturele klaskamers. Dit kan egter deur sowel die betrokkenheid as die afstand wat 'n pikturale humorstudie bied, ontlont word. In die toenemende beweging na en klem op die virtuele leeromgewing bied strokiesprente 'n ideale 
medium om die addisioneletaalleerder se kulturele en visuele geletterdheid op 'n interessante en genotvolle manier deur middel van rekenaarprogramme te bevorder. Daarbenewens word die leerder ook daadwerklik by die leerproses betrek indien 'n rekenaarondersteunde taalonderrigprogram (hierna ROTO-program genoem) interaktief ontwerp word.

By die ontwerp van 'n ROTO-program behoort daar op tekentradisies en strokiesprente as visuele tekste gelet te word, asook hoe sulke humoristiese tekste tot die ontwikkeling van visuele en kulturele geletterdheid in die omgewing van die Afrikaans-taalklas kan bydra. Die fokus kan meer spesifiek op leerders se ontvangs van Afrikaans as 'n addisionele taal val waar sekere fasette en 'n paar verrassende taalgebruiksmoontlikhede onderrig kan word.

Visuele geletterdheid kan lesers intellektueel en emosioneel bemagtig, en skakel ook die gedrukte teks se monopolie op 'n mens se simboliese omgewing uit. Daarom is dit belangrik om leerders in taalonderrig toe te rus om visuele boodskappe te vertolk. Omdat visuele geletterdheid in 'n groot mate van die ontvanger se verwysingsraamwerk afhang, is dit ook nodig om kulturele geletterdheid ten opsigte van die verworwe taal te ontwikkel. Kulturele geletterdheid kan as die netwerk van agtergrondkennis beskryf word wat mense in staat stel om grappies, verwysings, assosiërings, metafore, ensovoorts te verstaan (Combrink, 1996:185). Uit 'n literêr-pedagogiese oogpunt kan die humor in die tekeninge van T.O. Honiball as kulturele manifestasies beskou word, en sy strokiesprente as kuns wat daaruit ontstaan het (Verster, 2003; Kruger, 2004). Met betrekking tot pikturale humor, kan die aanduidende, konnotatiewe en ideologiese assosiërings wat deur beelde opgeroep word, bestudeer word as deel van die ontwikkeling van leerders se visuele geletterdheid (Considine, 1987). Combrink et al. (1997:77) meen dat die term visuele geletterdheid verwys na die vaardigheid om 'n visuele teks se inhoud te bestudeer, analiseer en interpreteer. Dit sluit in die ontwikkeling van die kyker se vermoë om tekens, simbole, indekse en ikone te begryp, dit wil sê die kodes wat gebruik word om die boodskap mee oor te dra.

Met behulp van die bestaande verwysingsraamwerk van strokiesprentgebruike, kan die onderwyser addisioneletaalleerders help om hulle visuele vaardighede te ontwikkel. Visuele vaardighede behoort die ontvangers se positiewe belewing van strokiesprente te verhoog en daardeur hulle belangstelling in lees te verbeter (Le Cordeur, 2003; 2004).

Met betrekking tot visuele en kulturele geletterdheid voer hierdie artikel aan dat die strokiesprente en tekeninge van T.O. Honiball - as weerspieëling van middelklaskultuur in teenstelling met hoëklas- of laeklaskultuur - onontginde en onverkende potensiaal as onderrigmateriaal vir addisioneletaalleerders van Afrikaans inhou. Honiball se strokiesprente kan dus tot 'n doeltreffende en subtiele proses vir die aanleer van Afrikaans as 'n addisionele taal bydra, terwyl dit ook 'n nuwe belangstelling in Afrikaanse letterkunde kan aanwakker.

Die artikel bespreek die ontwikkeling van 'n ROTO-program wat op 'n Adoons-episode ('n storie wat op langspeelplaat deur 'n bekende en gewilde radio-omroeper, wyle Dana Niehaus vertel is) en 'n Adoons-Kersfoto berus. 'n Oom Kaspaas-storie is as bonus ingesluit. Laasgenoemde is 'n tekenprent van een van die strokies wat vir 'n televisie-uitsending van die destydse Uit en Tuis-program geskep is.

Met inagneming van die beginsels van addisioneletaalonderrig in besonder, het die navorser as instrukteur in die ROTO-program 'n kommunikatiewe omgewing met betekenisvolle taaltoevoer geskep wat leerders help om hulle Afrikaanse woordeskat te verryk en die gebruik daarvan aan te moedig (Ybarra \& Green, 2003). In so 'n omgewing het die leerders 
deurlopende toegang tot die teikentaal, met uitkomsgerigte aktiwiteite wat hulle aanmoedig om binne die konteks wat geskep word te kommunikeer (deur take soos die herkenning van en betekenisskepping met woorde en frases, die aanleer van nuwe uitdrukkings, ens.).

\section{AFRIKAANSE FOLKLORE AS PIKTURALE HUMOR VIR ADDISIONELETAAL- ONDERRIG}

Addisioneletaalleerders koester dikwels negatiewe stereotipes van die teikentaal se moedertaalsprekers. In die geval van Afrikaans het apartheid dié probleem in die nabye verlede vir moedertaalsprekers vererger. Selfs die teikentaalsprekers mag ontgogeld voel met die politieke bagasie wat hulle (onwillig) saamdra, en meen dat die nuwe samelewing hulle identiteit as minderwaardig ag. In teenstelling met wat addisioneletaalleerders dalk dink, is moedertaalsprekers dikwels op soek na 'n subjektiewe waardebepaling van hulle tradisies, en wonder hulle of hulle eie kultuur die moeite werd is. In hierdie verband kan daar na die onlangse debat oor die De la Rey-liedjie van Bok van Blerk in die gedrukte en elektroniese media verwys word (Rapport, 18 Februarie 2007; www.litnet.co.za).

Hoewel kulturele inhoude soms negatief vertolk word, kan dit ook verrykend en dinamies wees, mits onderwysers sensitief en gebalanseerd daarmee omgaan. Dit is 'n ryke bron van kulturele geletterdheid en kultuurskepping wat wag om ontgin te word (Kruger, 2002).

Hoewel taal in enige kultuur 'n belangrike rol speel, meen Kamwangamalu (1997:245) dat mense nie noodwendig gevangenes van hulle taal is nie, maar dat hulle taalgebruik wel hulle wêreldbeskouing weerspieël. In dieselfde trant beklemtoon Trivedi (1978:92) dat blootstelling aan die teikentaalkultuur die aangeleerde gedrag en waardes van addisioneletaalleerders kan uitdaag en positief ontwikkel. Leerders se letterkundewaardering kan byvoorbeeld deur die insluiting van folklore in die vorm van 'n spel met idiomatiese uitdrukkings versterk word. Hulle visuele geletterdheid kan weer ontwikkel word deur waar te neem hoe stereotipe karakters, liggaamstaal en gedrag uitgebeeld word.

Volgens Miruka (1994:183) is 'n belangrike funksie van folklore dat dit tot kognitiewe stimulering kan bydra. Hier kan spesifiek verwys word na sensoriese bewuswording, metaforiese denke en die benoeming van voorwerpe en gebeure, asook die emosionele ontwikkeling wat met die ontleding van gewilde voorbeelde, soos die (dikwels absurde en parodiese) gebruik van spreekwoorde gepaardgaan. Figuurlike taalgebruik kan tot die uitskakeling van emosionele struikelblokke in taalonderrig bydra omdat dit 'n vorm van beeldrykheid verteenwoordig wat lank reeds deel van alle mense is, en selfs terapeutiese waarde kan hê (Engelbrecht, 1990:96).

Die Toegepaste Folklorestudieraamwerk (Spitzer, 1992:83) skep 'n platform vir Afrikaanse folklore om mense te help om hulle ambivalensie te ondersoek, selfs terwyl hulle met die verwoording van die boodskap hulp soek. Dit het op sowel addisioneletaalleerders as moedertaalsprekers van Afrikaans betrekking. Folklore kan 'n nuttige medium wees om 'n brug te bou, sodat emosionele probleme (soos gevoelens van skok, hulpeloosheid, taal-angs, vrees vir mislukking of gebrekkige motivering) wat die leerproses kan belemmer, teengewerk kan word (Trivedi, 1978:93, 95). Folklore kan ook help om kultuuroordrag te vertolk of te verstaan (Kruger, 2001). 
Degh (1994 in Thosago, 1999:3) formuleer enkele kenmerke van folklore: Dit moet sosiaal relevant wees; tradisie as grondslag hê, en vir huidige behoeftes toepaslik wees. Thosago is 'n voorstander van 'n materialistiese benadering tot folklore-studie:

Its irresistable allure to mass industrial culture enables it to interpenetrate and survive in various levels of the social and economic [lees: opvoedkundige] strata where traditional products are translatable into new commodities for consumption by both the local and the newly emerging global communities... (Thosago, 1999:4)

Folklore is 'n soort kernliteratuur, 'n oorgelewerde verwoording van die gebeure en waardes wat inherent deel uitmaak van die menslike spesie. Juis as gevolg hiervan kan enige leerder hom-/haarself daarmee vereenselwig, want dit handel oor en spreek tot die mens se basiese behoeftes, die vermoë om te groei, te voel, te kommunikeer, die werklikheid deur sy verstand te beheer en 'n geestelike dimensie te beleef (Kruger, 2001). Uiteindelik kan leerders deur middel van die bekende agtergrond/inhoud van 'n folklore-teks van die omvang van die taal self bewus word, met al die betekenisdiepte en -inhoud wat daarin opgesluit lê. Die graad van verstaanbaarheid waarmee 'n addisioneletaalleerder betekenis in folklore kan skep, word deur die leser se persoonlike betrokkenheid beïnvloed, wat weer op sy beurt tot die leser se kreatiewe wisselwerking met en deelname aan die teks kan lei - van die meganiese tot die ontledende aspek van die taalstelsel.

Deur middel van Afrikaanse folklore-tekste in ROTO-programme kan die leerder ontdek hoe gebeure ontvou, en deur middel van interaktiewe deelname sy emosionele ervarings en persoonlike reaksie deel. Die relevansie van 'n goeie leesteks (ongeag die oorsprong) lê daarin dat die leerder deel van die teks word (en persoonlik daarmee in 'n tweegesprek tree). Op hierdie manier word die taal deursigtig (Moyo, 1997:47).

Volgens Spitzer (1992:80) skep folkloriste binne en dikwels buite die grense van 'n gemeenskap openbare dialoë oor tradisionele kultuur. Tussen folkloriste en die kultuur waarbinne hulle optree, word mense se kulturele betekenis gevorm deur die metafore wat reeds tot hulle beskikking is en dié wat hulle skep. Nuwe metafore vir mense se geloof in die waarde van kulturele verskeidenheid, gelykheid en gelykmatigheid sal hulle help om hulle werk beter te verstaan, aan te bied en te verduidelik aan die baie gehore wat wil luister, kyk en lees. Almal beoordeel hulle verhoudinge tot kulturele tradisie bewustelik of onbewustelik aan die hand van die metafore wat hulle erf of skep (Spitzer, 1992:99).

In twee afsonderlike artikels voer Thosago (1999; 2004) aan dat 'n herlewing van folklore deur middel van die kuberruimte kan plaasvind, en dat dit as metafoor gepas is in die postmoderne paradigma. Die rede hiervoor is volgens hom juis folklore se inherente kenmerke soos 'n hibridiese karakter, sinkretisme en metafiksionaliteit. Voorbeelde hiervan kan in hedendaagse advertensies, modes en films soos Jurassic Park, Shrek en Harry Potter gevind word, asook in wetenskapfiksie wat sterk op intertekste op grond van tradisionele literatuur steun.

Thosago (2004:16) noem strokiesprente en spotprente as voorbeelde om sy argument te staaf - 'media forms with unlimited potential to obliterate what is supposedly "antique" ... about folklore'. Ook voer Thosago (1999:3) aan dat folklore ongetwyfeld kenteoretiese neigings toon wat direk uit die volgehoue kontak met die snelveranderende omgewing vloei waarin dit naas die massamedia en ander ontluikende tegnologieë bestaan. Schenda (1992, in Thosago, 
1999:3) beweer dat wanneer folklore herskep en in nuwe kontekste geplaas word, daar 'n nuwe folklore-genre ontstaan. Die massamedia se potensieel wesenlike bydrae tot die instandhouding en skepping van folklore blyk dus duidelik hieruit.

Jansen (1965:51) is van mening dat folkloriste op strokiesprentverhale en televisiereekse behoort te konsentreer en daaruit moet put om betekenis te skep sodat die kulturele erfenis vir ingewyde (moedertaalsprekers) sowel as oningewyde (anderstalige) gebruikers tot sinvolle ervaring en begrip kan lei. Die argument in hierdie verband kan gestaaf word deur na kontekstuele folkloriste se gemoeidheid met die omgewing waarin die folklore-teks veranker is, te verwys (Dorson, 1972:45).

Folklore word, volgens Thosago (1999:5), namate nuwe geslagte ontstaan, dinamies in nuwe verhoudinge verweef, en met die koms van elke nuwe konteks neem die eietydse wêreld gretig aspekte van hierdie ou tradisie op en eien homself dit toe. Wanneer dit mondelings, elektronies of in gedrukte vorm oorgedra word, is die meeste folklore-genres geneig om 'n groot deel van die fundamentele eienskappe daarvan te behou, aangesien die manier van oordrag nie noodwendig die waarde en status daarvan as folklore verminder nie. As gevolg van die beskikbaarheid en toeganklikheid van elektroniese oordragstelsels vergroot die moontlikheid dat folklore anderstaliges kan bereik aansienlik (Thosago, 1999:5).

T.O. Honiball se strokies kan as toegepaste Afrikaanse folklore beskou word (Kruger, 2004), hoewel nie alle folklore-spesialiste strokiesprente soos dié as deel van die folklore-kategorie beskou nie - volgens sommige sluit dit nie uitdruklik mondelinge tradisies in nie (Utley, 1972:10). Tog het enkele voorbeelde van Honiball se pikturale humor uit die 'Jakkals en Wolf'-intertekstradisie van mondelinge volksverhale wat geslagte lank oorvertel is gespruit, en is dit ook daarop gegrond (Steenberg, 1987:34). Daarom kan Adoons-hulle (1977a) en Wolf en Jakkals van Uilekraal (1978) as deel van die massakulturele folklore beskou word (Dorson, 1972:41) waarin die eietydse stadslewe deur die massamedia uitgebeeld word. Oom Kaspaas in die knyp (1979) het ook uit mondelinge grootliegstories ontstaan, en is gegrond op 'n groot, spogsieke karakter in die Bosveld wie se stories boemerang en hom gevolglik altyd die voorwerp van spot mak (Verster, 2003:370). Hierdie stories van Honiball verskaf interessante leergeleenthede in die addisioneletaalklas, veral oor die elemente van humor in die diereverneukers (Finnegan, 1970:344), komiese situasies, liggaamstaal en taalgebruik (byvoorbeeld sommige karakters se byname).

\section{ONTWIKKELING VAN 'N VIRTUELE KLASKAMER MET DIE PIKTURALE HUMOR VAN HONIBALL}

Ten spyte van die kritiek teen die konstruktivistiese benadering tot leer, is hierdie benadering in die ontwikkeling van die ROTO-program met Honiball se strokies gevolg. Volgens hierdie leerteoretiese paradigma bou die leerder sy eie kennis binne 'n gegewe, egte konteks op, waarbinne betekenisvolle leer plaasvind sonder dat dit op blote memorisering berus. Die leerinhoud van die betrokke ROTO-program is ontwerp om 'n dinamiese verhouding tussen die leerder en die leermateriaal tot stand te bring wat die leerder toelaat om risiko's te loop, keuses te maak en selfstandig volgens sy eie pas en leerstyle te vorder (Nelson, Bueno \& Huffstutler, 1999; Shulman, 2001).

Die navorser as instrukteur wou graag met die ROTO-program die volgende doelwitte bereik: 
- die bied van multimedia wat leerders en onderwysers sal help om 'n konseptuele begrip van pikturale humor te ontwikkel;

- blootstelling van minder bekende Afrikaanse folklore aan addisioneletaalleerders in 'n vernuwende onderrigkonteks. Die bedoeling is om met die program vir leerders 'n nuwe ervaring en erkenning aan kulturele erfenis te bied in ooreenstemming met die uitkomsgebaseerde onderwysbeleid se kritieke uitkoms dat leerders se estetiese en kulturele sensitiwiteit ontwikkel behoort te word;

- 'n interaktiewe, multisensoriese en multimedialeeromgewing (oudiovisuele, lewendige, emosionele, kommunikatief-kognitiewe aanbieding van interkulturele aspekte) wat saam met klaskameronderrig vir addisioneletaalleerders van Afrikaans gebruik kan word;

- bevrediging van die leerder se inhoudsverwagtinge en -behoeftes, en interaktiewe begeleiding in die strewe na uitgebreide kennis en vaardighede;

- leeraktiwiteite wat vir die leerder beheerbaar is, met bepaalde aandag aan volgorde, pas/tempo, aanbiedingsmedium en ingewikkeldheidsvlak ten opsigte van rekenaarprogrammatuur;

- leerderblootstelling aan voorbeelde van Afrikaans wat merendeels bekende woordeskat en grammatiese strukture in 'n kommunikatiewe program gebruik;

- geleenthede vir leerders om deur middel van folklore op taalvoorbeelde te reageer deur aan 'n verskeidenheid doelgerigte aktiwiteite en outentieke take (praat, luister, lees) deel te neem wat herkenning, memorisering, herhaling en betekenisassosiëring met woorde en frases insluit;

- relevante hulpbroninligting wat die volgende insluit: woordelyste met uitgesoekte woordeskat; teks wat kontekstuele en agtergrondinligting voorsien; tekstranskripsies van uitgesoekte videosegmente, en skakels vir die luister na uitgesoekte woorduitsprake en vrae;

- 'n inleidende skermbeeld wat leerders ten opsigte van die onderrigdoelwit oriënteer, en hulle nooi om deur 'n reeks taakgerigte leeraktiwiteite te blaai wat die volgende standaardvrae bevat: Vul die oop spasie in; soek pasmaats; watter een van (a), (b) of (c) is die regte antwoord; gee 'n kort antwoord; sleep en los, en watter stelling is waar/onwaar;

- onderrigmetodes wat leerders toelaat om verskillende leermetodes te gebruik en hulle nie te dwing om een aktiwiteit af te handel voor hulle na die volgende voortbeweeg nie.

In die ontwerp van die betrokke ROTO-program was dit belangrik om seker te maak dat die kontekste en take relevant is, en dat konseptuele begrip ontwikkel word (in navolging van die voorbeeld beskryf deur Nelson et al., 1999). Daar is op 'n gelyklopende ontwerp- en ontwikkelingsproses besluit waarvolgens elke module ontwikkel is, eerder as om vir die voltooide ontwerp te wag.

Die tekste is gekies om binne hoërskoolleerders se rekenaarervaringswerklikheid te pas; dit is immers bekend dat een-en-twintigste-eeuse leerders hulleself graag met rekenaarspeletjies vermaak en op die internet rondrits. Verder pas dit in by hulle belangstellingsveld van massamedia, wat in al hoe meer vorme beskikbaar is, byvoorbeeld visuele beelde, grafika, beweging, klank en kleur. Al dateer die Honiball-tekste uit die tagtigerjare, word dit wel op 'n leerdergerigte wyse in die ROTO-program aangebied. 
Op hoërskoolouderdom geniet leerders grappies, poetse, byname en pikturale humor wat op komiese lyftaal, karikature en situasiehumor berus. Die Adoons-storie handel oor die onnut Fielies, wat sy familie onwetend in die moeilikheid laat beland, terwyl die Kersfoto vir die meeste families steeds 'n bekende tradisie is. Terwyl die leerders hulleself op hierdie manier met karakters en gebeure in die tekste kan vereenselwig, kan hul kulturele horisonne verbreed ten opsigte van Afrikaanse toegepaste folklore om by die HNK-verklaring (Departement van Onderwys, 2003) se ontwikkelingsuitkomste te pas. Laasgenoemde vereis dat leerders in verskeie sosiale kontekste kultureel en esteties sensitief moet ontwikkel, en dat leerders se kulturele horisonne ten opsigte van Afrikaanse toegepaste folklore verbreed. Die multimedia wat gebruik is, help onderwysers as fasiliteerders om die belangrike uitkomste van kommunikasie en die doeltreffende gebruik van tegnologie te verwesenlik deurdat dit die wisselwerking tussen die leerder en die materiaal verhoog.

Die program bestaan uit keuses en voortdurende positiewe, konstruktiewe terugvoering wat die leerder help om sy eie vordering deur middel van 'n leersiklus te evalueer wat uit waarneming, integrasie en motoriese aksie bestaan (Terhart, 2003:36; Zull, 2002). Daar word dus in beginsel aanvaar dat leerders deur ervaring (Kolb, 1984; Kelly, 1997), dade (Felder \& Brent, 2003) en die regstelling van hulle eie foute sal leer (Terhart, 2003:35, 36). Navorsing toon dat die virtuele klaskamer potensieel 'n gestruktureerde omgewing skep waarbinne leerders se aandagspanprobleme hanteer kan word (Rizzo et al., 2000). ROTO-programme maak aanspraak op leerders se toegespitste aandag, volgehoue aandag, selektiewe aandag en afwisselende aandag, en help op hierdie manier bepaald as terapie vir verdeelde aandag - 'n probleem wat toenemend by jong kinders voorkom wat juis as gevolg van die een-entwintigste eeu se inligtingsoorlading hiperaktief is.

Binne die konteks van toegepaste folklore met T.O. Honiball se tekste, is verskeie outentieke take geskep wat leerders se kommunikasievaardighede ontwikkel. Die ROTO-program is ingevolge Mayer (2003) se vier metodes geskep wat tot die doeltreffende ontwerp van rekenaaronderrigprogramme kan bydra, naamlik die multimedia-effek, die samehang-effek, die ruimtelike-aangrensingseffek en die verpersoonlikingseffek. Mayer (2003) voer aan dat 'n dieper leerproses met 'n multimediaverduideliking as met 'n blote verduideliking in woorde by leerders plaasvind. Dit het betekenisvolle implikasies vir addisioneletaalleer, en bied 'n verklaring vir die insluiting van oudiovisuele media by die Adoons-storie (vgl. Kruger, 2004:165-168 se bespreking van tersaaklike onderrigstrategieë wat rekenaarmatig in die ROTO-program aangebied is).

Die samehang-effek verwys na die bevinding dat leerders beter leer wanneer die onderrigmateriaal betekenisvol is en inligting uitsluit wat nie relevant is nie. Hierdie bevinding sluit aan by Krashen (1985) se betekenisvolle toevoerhipotese wat veral op addisioneletaalonderrig van toepassing is. Die begripsoefeninge by die Adoons-storie asook die legkaartoefening oor die Adoons-Kersfoto berus op die samehang-effek omdat die visuele media wat die verbale teks ondersteun telkens toepaslik is en nie onnodige inligting verskaf nie. Mayer (2003:133) meen dat nieverwante inligting met die leerder se aandagspan kan inmeng, selfs al is die inligting interessant. Dit is omdat nieverwante inligting die leerders se kousaleverbandsketting, wat in die organiseringsproses gevorm word, onderbreek; dus word nietersaaklike skemas gesoek waarmee die visuele en verbale toevoer verwerk word.

In die luister-, begrips-, uitspraak- en legkaartoefening is daar veral van die ruimtelikeaangrensingseffek gebruik gemaak, waar ooreenstemmende woorde en prente naby mekaar in 
plaas van ver uitmekaar op die skerm verskyn. Hierdie onderrigmetode ondersteun die leerder se werkende geheue, want dit bevorder die proses waardeur visuele en verbale modelle deur die leerder geïntegreer word - 'n sleutelfaktor in aktiewe leer.

Die verpersoonlikingseffek speel 'n belangrike rol in die ROTO-program. Die unieke vertelstyl van Dana Niehaus by die Adoons-storie, die gebruik van ouditiewe vrae in die luisteroefening, asook die positiewe ouditiewe en visuele verbale kommentaar op leerders se pogings om vrae te beantwoord, dra daartoe by dat die onderrigprogram in 'n gesprekstyl eerder as ' $n$ formele styl aangebied word. Dit sluit dus aan by die voorbeelde wat Mayer (2003:133) noem aangesien die media tekenprente en vertelling, asook tekenprente met teks op die skerm insluit.

In die vorm van byvoorbeeld tweegesprekke met praatroetines, asook verbandhoudende dagboekinskrywings bied die Kaspaas-tekenprent aan die einde verdere onderrigmoontlikhede waarmee leerders se skryfvaardighede ontwikkel kan word (Cunningham, 2000; Cunningham, 2002). Leerders kan ook aangemoedig word om binne die konteks van hierdie stories deur middel van e-pos met mekaar te kommunikeer en so hulle nuutverworwe woordeskat te gebruik (Lawrence, 2004).

Om vir leerders se onderskeie leerstyle en taalontwikkelingsvlakke voorsiening te maak, is woordelyste, grammatiese en kontekstuele inligting, woordklanke en prente vir verwysing, asook korrekte antwoorde vir terugvoering vir elke oefening binne die program beskikbaar gestel.

Die interaktiewe take in die ROTO-program bestaan uit die volgende:

- 'n luisteroefening waarin leerders na begripsvrae luister wat op die Adoons-episode gegrond is, terwyl hulle ook na die gepaardgaande prentjie kyk;

- 'n uitspraakoefening waarin leerders op 'n omraamde woord in die strokieteks kliek, na die instrukteur se uitspraak daarvan luister, en dan self die woord uitspreek, waarna hulle na hulle eie stem kan luister. Vir hierdie oefening is daar in besonder op woorde in die teks gekonsentreer wat met geronde klanke, diftonge en woorde wat addisioneletaalleerders (bepaald Engelssprekendes) moeilik uitspreek, verband hou (byvoorbeeld lang en kort klinkers, en die fonetiese onderskeid tussen [v] en [f], [g] en $[\mathrm{x}]$, [j] en [h] soos in aankom, stilstand, gevaarte, gespuis, vakansie, Keesje, hulle, ens.);

- taaloefeninge waarin die leerder selfstandige naamwoorde en werkwoorde binne die strokie moet herken en identifiseer, en voorsetsels binne die konteks van die gegewe sinne in die strokie moet intik;

- vrae oor humor en visuele geletterdheid wat veral met die herkenning van soorte humor, voegwoorde en woordorde, soos van toepassing op die Adoons-strokie, verband hou. (Leerders wat hiermee probleme ervaar, kan op omskrywings as hulpbron kliek.);

- 'n legkaartoefening waarin leerders karakters en aksies in die Adoons-Kersfoto met behulp van byvoeglike naamwoorde en bywoorde moet beskryf; en

- 'n blokraaiselwoordewar waarin leerders aan die hand van verskeie leidrade na idiomatiese uitdrukkings moet soek wat binne die konteks van die Adoons-Kersfoto pas. 
Die volgende stappe is gevolg met die ontwerp van die ROTO-program wat in die navorsingsprogram gebruik is (Kruger, 2006):

Eerstens is 'n ontwikkelingspan en multimediaprogrammatuur in Augustus 2001 geïdentifiseer. Die span het bestaan uit die instrukteur met onderrigervaring op die gebied van inhoud en die onderrig van Afrikaans as 'n addisionele taal, 'n grafiese ontwerper met kennis van en ervaring met bruikbaarheidsmanipulasie, en spesialiste op die gebied van multimediaprogrammatuurontwikkeling wat die proses kon moniteer. In die vroeë ontwerpfase is daar besluit om van Authorware 6.5 (opvoedkundige weergawe, 1987-2002) en WebCT gebruik te maak, en om die program gedurig met die oog op die hersiening van die prototipe te toets.

Tweedens het twee studentassistente (onderwysstudente) in Mei 2002 deur die program gewerk om enige moontlike haakplekke te identifiseer. Hiervoor moes hulle hoofsaaklik op tegnologiese haakplekke bedag wees, en dit in onderhoude wat met hulle gevoer is, aanmeld. Geringe tegnologiese foute is hersien en reggestel.

Derdens het voorgraadse Opvoedkundestudente in Oktober 2002 deur die program gewerk en vraelyste ingevul wat inligting oor die suksesvolle/gebrekkige bereiking van die programdoelwitte ingewin het. Kollegas wat nasionaal daarvoor bekend is dat hulle rekenaartegnologie in taalonderrig gebruik, is in November 2002 genader om die nuttigheid en opvoedkundige waarde van die program te evalueer. In hierdie fase het die ontwerpspan veral besef dat die gebruik van WebCT vir afstandgebruikers problematies blyk te wees, aangesien die kollegas se terugvoering getoon het dat toegangsverkryging tot hierdie USintranetwerk tydrowend is en dit hulle daarvan weerhou het om dit te voltooi. As gevolg hiervan het baie min kollegas volledige terugvoering gegee, hoewel hulle aanvanklik baie entoesiasties daaroor was om dit te gebruik. In hierdie stadium is daar besluit om die begripsvrae wat slegs op WebCT ontwikkel is, aan te pas en soos die res van die program na Authorware oor te dra. Die begripsvrae op WebCT is egter behou sodat dit steeds vir onderwysstudente van nut kon wees. Terwyl die program vir gebruik op Authorware aangepas is, is 'n ekstra woordewar-oefening ingevoeg om tot die gebruiker se kennis en begrip van idiomatiese uitdrukkings binne die konteks van die Adoons-Kersfoto by te dra.

Vierdens het graad 10-leerders van drie Stellenbosch-hoërskole die program in Mei 2003 gebruik, en reaksievrae skriftelik beantwoord om die opvoedkundige waarde van die program met betrekking tot kommunikatiewe onderrigbeginsels te bepaal. Hierdie leerders het ook 'n humorbelangstellingsvraelys ingevul sodat 'n profiel saamgestel kon word om aan te toon in watter mate hulle humorsmaak deur bestaande massamedia (films, televisie, advertensies, grappies, stories) bepaal word.

Ná voltooiing van die program is 'n nuwe groep onderwysstudente in 2004 daaraan blootgestel (Kruger, 2006). Hulle moes ook die humorbelangstellings- en humorstylvraelys invul, en moes aan die hand van 'n aantal gestruktureerde vrae krities op die opvoedkundige waarde van die program binne 'n addisioneletaalonderrigkonteks kommentaar lewer.

\section{NAVORSINGSPROGRAM}

In genoemde navorsingsprogram (Kruger, 2006) moes onderwysstudente aan die begin van September 2004 aan die hand van addisioneletaal-onderrigbeginsels 'n ROTO-program met 
pikturale humor op grond van Honiball se folklore vir die onderrig van Afrikaans as 'n addisionele taal beoordeel, nadat hulle aan Krashen (1985) se monitorteorie blootgestel is (Black, 1986; Blacquière, 1989; Botha, 1989).

Die doel met hierdie studente se blootstelling aan die ROTO-program was om hulle van die gebruik van rekenaars en Afrikaanse folklore in die onderrig van Afrikaans as 'n addisionele taal bewus te maak, sodat hulle daardeur die beginsels van rekenaarondersteunde onderrigprogramme, asook die toepassing van die kommunikatiewe en taakgerigte benaderings tot taalonderrig in addisioneletaalonderrig deur ervaringsleer kon leer ken.

In die studente se beoordeling van die ROTO-program vir addisioneletaalleerders was dit belangrik om vas te stel of hulle as voornemende onderwysers die kontekste en take as relevant ervaar het, en of konseptuele begrip na hulle mening daardeur ontwikkel kan word (Nelson et al., 1999). Die navorser wou bepaal of die betrokke multimedia hulle as onderwysers en fasiliteerders kan help om enersyds die bepaalde taalleeruitkomste vir addisioneletaalonderrig te bereik, en andersyds die belangrike uitkomste van kommunikasie en die doeltreffende gebruik van tegnologie te laat verwesenlik. Daardeur kon die bereikbaarheid van die ROTO-program se doel, naamlik om die wisselwerking tussen die addisioneletaalleerder en die pikturale humormateriaal te verhoog, bepaal word.

Die gestruktureerde opdrag om die onderwysstudente se beoordeling van die ROTO-program aan die hand van addisioneletaalonderrigbeginsels te rig, was dat elkeen hulle evaluering van die program met betrekking tot die genoemde interaktiewe take moes neerskryf en moes meld vir watter graad die program gebruik sou kon word (Kruger, 2006).

Nadat die studente aan die ROTO-program blootgestel is, het hulle 'n gestruktureerde vraelys met spasies vir antwoorde ingevul. Net twaalf studente het hulle vraelyste ingedien. Aangesien dit oop vrae was, was hulle vry om enige kommentaar te lewer, en het daar by sommige vrae meer as een soort kommentaar voorgekom. Die tendense in die studente se beoordeling van die ROTO-program as addisioneletaal- Afrikaansonderrigstrategie kan soos volg opgesom word:

- Die meeste oefeninge het baie positiewe kommentaar uitgelok, en heelwat emosiebelaaide woorde soos 'lekker', 'pret' en 'opwindend' is gebruik om te toon dat die studente dit werklik geniet het.

- Die uitspraakoefening was vir die studente minder aangenaam, maar tog het hulle opgemerk dat dit wél vir addisioneletaalleerders nuttig behoort te wees. Uiteraard het hulle as moedertaalsprekers dit meer vervelig gevind.

- Die meeste van die studente het die humorvrae moeilik gevind en gemeen dat dit vir addisioneletaalleerders aangepas behoort te word.

- Veral die uitspraak- en taaloefeninge het die studente klaarblyklik tot kritiese denke gestimuleer.

- Daar is verskeie oefeninge waarmee meer as een student tegniese probleme ondervind het.

- Die meeste studente het die woordelys as 'n goeie naslaanbron vir addisioneletaalleerders ervaar en gemeen dat dit baie toeganklik en maklik was om woorde daarin na te slaan. Een van die studente het dit self nodig gekry, en dit as 'n nuttige bron vir die verklaring van nuwe en moeilike woorde en begrippe ervaar. 
Uiteindelik het die studente in die algemeen die program as nuttig vir graad 8, 9 en 10 in die addisioneletaalkonteks ervaar. Een student het opgemerk dat dit vir al die grade, selfs vir graad 12, gebruik kon word (hoewel dit 'n ander benadering sou verg), omdat alle leerders visueel gestimuleer wil word. Uit die belangstellingsvraelys wat die meeste studente ingevul het, was dit duidelik dat Honiball se Adoons- en Oom Kaspaasstories vir baie studente onbekende humormateriaal was (Kruger, 2006).

\section{SAMEVATTING}

Die navorsingsgevolgtrekkings was dat ROTO-programme met mediatekste, kultuur en humor in die onderrig van Afrikaans as 'n addisionele taal gebruik kan word om taaluitkomste (lees en kyk, luister, praat, skryf en taalstrukture) te bereik. Deur die gebruik van ROTOprogramme met humormateriaal, kan leerders se visuele en kulturele geletterdheid in die onderrig van Afrikaans as 'n addisionele taal bevorder word. Verder bied die virtuele klaskamer die moontlikheid om addisioneletaalleerders daadwerklik by humoronderrig te betrek.

Die navorsingsprogram het getoon hoe visuele geletterdheid in die ROTO-program by humor en die rekenaar as visuele medium geïntegreer is. Die visuele kant van nieverbale kommunikasie, naamlik liggaams- en gebaretaal, is wyses van kommunikasie wat deur mense van verskillende kulture gebruik kan word (hoewel lande en tale se gebaretaalgrammatika ongetwyfeld verskil). Ten spyte van die verskille in gebaretaaluitdrukkings, toon dit 'n interessante ooreenkoms met gewone liggaamstaal, waarvan elke leerder bewus kan word en wat in enige interpersoonlike kontak en kommunikasie ' $n$ rol speel.

Soos wat die taal/boodskap van musiek deur alle mense gedeel en/of verstaan kan word, kan die nieverbale (visuele) aspekte en wyses van kommunikasie met vrug in die virtuele taalklaskamer gebruik word. Taalverwerwing word op dié manier deel van die alledaagse (kulturele en visuele) werklikheid, en bly nie net 'n intellektuele oefening en geïsoleerde afdeling nie. Leerders se visuele geletterdheid sal hulle ook daartoe in staat stel om pikturale humor te verstaan en te waardeer.

Die studente in die genoemde navorsingsprogram se beoordeling van die ROTO-program vir addisioneletaalonderrig beklemtoon dat sodanige programme nuttig is vir die onderrig van Afrikaans as ' $n$ addisionele taal. Aangesien daar tans weinig daarvan bestaan, is dit moontlik om meer soortgelyke programme en rekenaarspeletjies vir addisioneletaalonderrig te ontwerp. Een beskikbare program is Woel met Afrikaans, wat ongelukkig met verouderde programmatuur werk (CD-ROM en stiffie). Hierdie program is moeilik bekombaar, baie duur en het vanweë die verouderde programmatuur beperkte gebruikswaarde in skole. Dit is wel 'n baie interessante en geïntegreerde lees- en speletjiesprogram wat die meeste van die taaluitkomste dek.

Dit bly moeilik om in besonder die skryfuitkoms op 'n rekenaarprogram te bereik, maar die moontlikhede van die integrasie van rekenaarkletskamers en e-pos brei steeds uit. Die gebruik van programme soos MECC Storybook Weaver en Microsoft Powerpoint verdien veral verdere navorsingsaandag omdat dit baie potensiaal vir die ontwikkeling van lees- en skryfvaardighede toon, juis omdat albei programme kan aanleiding gee tot die skep en gebruik van hipertekste in die virtuele klaskamer. Hierdeur kan leerders dus gestimuleer word om sowel kultuurgebruikers as kultuurskeppers te wees. 
Hoewel die graad 10-leerders wat gehelp het om die ontwikkeling van die program te toets nie deel van die navorsingsprogram was nie, was die genot waarmee hulle deelgeneem het veelseggend. Verder was daar in hul antwoorde op die vrae geen negatiewe respons op die Honiball-tekste nie; inteendeel, hulle het belangstelling daarvoor getoon en die situasiehumor in die strokie besonder baie geniet. Deesdae is daar egter meer resente strokiesprente in massamedia en op die internet in Afrikaans beskikbaar (of wat vertaal kan word) wat as hedendaagse toegepaste folklore met eweveel vrug omskep kan word in soortgelyke ROTOprogramme.

\section{VERWYSINGS}

BLACK, L. 1986. Kommunikatiewe taalonderrig, met spesiale verwysing na letterkunde-onderrig en eksaminering. Klasgids, April:62-74.

BLACQUIÈRE, A. 1989. Kommunikatiewe taalonderrig: Moontlikhede vir Afrikaans Tweede Taal. Klasgids, Mei:50-57.

BOTHA, L. 1989. Tweedetaalteorie vir die eerstetaalonderwyser. Per Linguam, 5(1):50-58.

COMBRINK, L. 1996. Kulturele geletterdheid en multikulturele onderwys. Tydskrif vir Taalonderrig, $30(1): 1-13$.

COMBRINK, L, N FAASEN, H GEYSER, \& A KLOPPERS. 1997. Taalkonteks. Johanneburg: Juta.

CONSIDINE, DM. 1987. Visual literacy and the curriculum: more to it than meets the eye. Language Arts, 64(6):634-640.

CUNNINGHAM, D. 2002. Languages, technology and teaching: Challenges and solutions for the 21st century. Tydskrif vir Taalonderrig, 35(4):201-222.

CUNNINGHAM, K. 2000. Integrating CALL into the writing curriculum. The Internet TESL Journal, 6(5). Mei. [Intyds]. http://iteslj.org. [26 November 2004].

DEPARTEMENT VAN ONDERWYS. 2003. Nasionale Kurrikulumverklaring Grade 10-12 (skole). Kaapstad: Departement van Onderwys.

DORSON, RM. 1972. Folklore and folklife. Chicago: University of Chicago Press.

ENGELBRECHT, MM. 1990. Selected techniques for reducing the affective filter in the English second language classroom. Ongepubliseerde MEd-tesis, Universiteit van Stellenbosch.

FELDER, RM \& R BRENT. 2003. Learning by doing. Chemical Engineering Education, 37(4):282283. E-pos van reis@stanford.edu aan Estelle Kruger [23 Januarie 2004].

FINNEGAN, R. 1970. Oral Literature in Africa. Oxford: Clarendon Press.

HONIBALL. TO. 1977. Adoons, Keesje, Kaas \& Kie. Kaapstad: Tafelberg.

HONIBALL, TO. 1979. Oom Kaspaas in die knyp. Kaapstad: Tafelberg.

HONIBALL, TO. 1986. Jakkals en Wolf van Uilekraal. Kaapstad: Tafelberg. 
JANSEN, WH. 1965. The esoteric-exoteric factor in folklore. In Dundes, A (ed.), The study of folklore. Englewood Cliffs, N.J.: Prentice-Hall. 42-51.

KAMWANGAMALU, NM. 1997. English and transformation to multicultural education in the new South Africa. Journal for Language Teaching, 31(2):243-252.

KELLY, C. 1997. David Kolb, the theory of experiential learning and ESL. Internet TESL Journal, 3(9): September. [Elektronies] http://iteslj.org [26 November 2004].

KOLB, D. 1984. Experiential education: Experience as the source of learning and development. Englewood Cliffs, NJ: Prentice Hall.

KRASHEN, SD. 1985. The input hypothesis: Issues and implications. Londen: Longman.

KRUGER, E. 2001. Die insluiting van 'n (multi-)kulturele komponent in die kurrikulum van Afrikaans as addisionele taal. Literator, 22(3):75-91.

. 2002. Folklore as a multi-cultural component in the literature curriculum for Afrikaans as additional language. Southern African Journal for Folklore Studies, 12(2):93-113.

. 2004. Die gebruik van strokiesprente deur T.O. Honiball vir die ontwikkeling van visuele en kulturele geletterdheid. Tydskrif vir Taalonderrig, 38(1):159-171.

2006. Die gebruik van humormateriaal in die onderrig van Afrikaans. Ongepubliseerde Ph.D.-proefskrif. Stellenbosch: Universiteit Stellenbosch.

LAWRENCE, DC. 2004. Rekenaargebruik vir die aanleer van Afrikaans. Ongepubliseerde D.Littproefskrif, Randse Afrikaanse Universiteit.

LE CORDEUR, MLA. 1991. Die integrasie van stelwerk- en letterkunde-onderrig met toespitsing op die media. Ongepubliseerde M.Ed.-verhandeling. Stellenbosch: Universiteit Stellenbosch.

.. 2004. Die bevordering van lees met media-onderrigstrategieë vir Afrikaans (graad 7): 'n Gevallestudie. Ongepubliseerde Ph.D-proefskrif. Stellenbosch: Universiteit Stellenbosch.

MAYER, RE. 2003. The promise of multimedia learning: Using the same instructional design methods across different media. Learning and Instruction, 13(2):125-139. [Elektronies beskikbaar: Science Direct]. [3 Desember 2004].

MIRUKA, O. 1994. Encounter with oral literature. Nairobi: East African Educational Publishers.

MOYO, T. 1997. Are the current high school literature texts of relevance of the culture of ESL learners? Journal of Language Teaching, 31(1):42-49.

NELSON, WA, KA BUENO \& S HUFFSTUTLER. 1999. If you build it, they will come. But how will they use it? Journal of Research on Computing in Education. 32(2). [Elektronies beskikbaar: EbscoHost, Academic Search Premier]. (3 November 2003].

RIZZO, AA, JG BUCKWALTER, MS BOWERLY, C VAN DER ZAAG, L HUMPHREY, U NEUMANN, C CHUA, C KYRIAKAKIS, A VAN ROOYEN \& D SISEMORE. 2000. The virtual classroom: A virtual reality environment for the assessment and rehabilitation of attention deficits. Cyber Psychology \& Behavior, 3(3):483-499. 
SHULMAN, M. 2001. Developing global connections through computer-mediated communication. The Internet TESL Journal, 7(6), Junie. [Elektronic]. Available: http://iteslj.org. [26 November 2004).

SPITZER, NR. 1992. Cultural conversation. Metaphor and methods in public folklore. In Baron, R. \& NR Spitzer, Public folklore. Washington: Smithsonian Institution. 77-103.

STEENBERG, E. 1987. Fantasie en die kinderboek - 'n kernhandleiding. Pretoria: HAUM-Literêr.

TERHART, E. 2003. Constructivism and teaching: A new paradigm in general didactics? Journal of Curriculum Studies, 35(1):25-44.

THOSAGO, CM. 1999. Folklore: From the fireplace to the marketplace. South African Journal of Folklore Studies, 9:1-11.

2004. The postmodern era: Tombstone or cornerstone of folklore? South African Journal of Folklore Studies, 14(1):12-18.

TRIVEDI, HC. 1978. Culture in language learning. English Language Teaching Journal, 32(2):92-97.

UTLEY, FL. 1972. Folk literature: An operational definition. In: R.M. Dorson (red.). Folklore and folklife. Chicago: University of Chicago Press. 7-24.

VERSTER, F. 2003. 'n Kultuurhistoriese perspektief op die pikturale humor van T.O. Honiball. Ongepubliseerde Ph.D.-proefskrif, Universiteit Stellenbosch.

YBARRA, R \& T GREEN. 2003. Using technology to help ESL/EFL students develop language skills. Internet TESL Journal, 9(3), [Elektronies]. http://iteslj.org. [15 April 2003).

ZULL, JE. 2002. Brain: Enriching teaching by exploring the biology of learning. [Electronic]. Beskikbaar: http://www.styluspub.com. E-pos van reis@stanford.edu aan Estelle Venter 2 Desember 2003.

\section{BIOGRAFIESE NOTA}

Estelle Kruger is verbonde aan die Departement van Kurrikulumstudies, Universiteit van Stellenbosch. Epos: ekruger@sun.ac.za 